\title{
Effects and mechanism of cerebroprotein hydrolysate on learning and memory ability in mice
}

\author{
L. An, X. Han, H. Li, Y. Ma, L. Shi, G. Xu, G. Yuan, J. Sun, N. Zhao, \\ Y. Sheng, M. Wang and P. Du \\ College of Pharmacy, Beihua University; Jilin, Jilin, China \\ Corresponding authors: P. Du / M. Wang \\ E-mail: dupeige2001@126.com / wangmanli@126.com
}

Genet. Mol. Res. 15 (3): gmr.15038804

Received May 16, 2016

Accepted June 3, 2016

Published July 25, 2016

DOI http://dx.doi.org/10.4238/gmr.15038804

Copyright $(C 2016$ The Authors. This is an open-access article distributed under the terms of the Creative Commons Attribution ShareAlike (CC BY-SA) 4.0 License.

\begin{abstract}
Cerebroprotein hydrolysate is an extract from porcine brain tissue that acts on the central nervous system in various ways to protect neurons and improve memory, attention, and vigilance. This study examined the effect and mechanism of cerebroprotein hydrolysate on learning and memory in mice with scopolamineinduced impairment. Mice were given an intraperitoneal injection of scopolamine hydrobromide to establish a murine model of learning and memory impairment. After 35 successive days of cerebroprotein hydrolysate treatment, their behaviors were observed in the Morris water maze and step-down test. Superoxide dismutase (SOD), $\mathrm{Na}^{+}-\mathrm{K}^{+}$-ATPase, and acetylcholinesterase (AChE) activity, and malondialdehyde (MDA), $\gamma$-aminobutyric acid (GABA), and glutamic acid (Glu) levels in the brain tissue of the mice were determined, and pathological changes in the hippocampus were examined. The results of the water-maze test showed that
\end{abstract}


cerebroprotein hydrolysate shortened the escape latency and increased the number of platform crossings. In the step-down test, cerebroprotein hydrolysate treatment prolonged the step-down latency and reduced the number of errors; cerebroprotein hydrolysate increased the activity of SOD, $\mathrm{Na}^{+}-\mathrm{K}^{+}$-ATPase, and AChE, reduced the levels of MDA, decreased the Glu/GABA ratio in brain tissue, and reduced pathological changes in the hippocampus. The results indicate that cerebroprotein hydrolysate can improve learning and memory in mice with scopolamine-induced impairment. This effect may be associated with its ability to reduce injury caused by free radicals, improve acetylcholine function, and modulate the Glu/GABA learning and memory regulation system, reducing excitotoxicity caused by Glu.

Key words: Cerebroprotein hydrolysate; Learning; Memory; Free radical injury

\section{INTRODUCTION}

Cerebroprotein hydrolysate is a small molecule consisting of peptides and amino acids that is separated and extracted from animal brain tissue. Typically, 15\% of the molecule consists of peptides and $85 \%$ of amino acids; its structure is completely consistent with imported cerebrolysin (Zuber, 1991; Zhang et al., 2005). Cerebroprotein hydrolysate also contains various other biologically active components, such as neurotransmitters, neuropeptide genes, neural nutrition factors, and nucleotides. It can easily penetrate biological membranes and pass through the blood brain barrier to promote cellular metabolism in a variety of ways. For example, it increases brain activity and is involved in oxidative processes in the body. It can also act on the central nervous system to regulate and improve the development and metabolism of neurons, induce the differentiation of neurons, promote the formation of synapses, and protect nerve cells from damage caused by ischemia, hypoxia, and neurotoxins (Sharp, 2002; Keilhoff et al., 2014). In addition, cerebroprotein hydrolysate can affect the respiratory chain by increasing the utilization of oxygen and glucose in the brain, subsequently, increasing the antioxidant capacity of brain tissues and the ability of the body to handle stress, improving energy metabolism in the brain, alleviating damage to brain tissues, and promoting recovery of brain function. In all, it has brain-strengthening, intelligence-improving, and brain-damage-repairing effects (Bannerman et al., 2008; Novak et al., 2009; García et al., 2011). Cerebroprotein hydrolysate products are important in widely used nutritional and healthcare medicines and have been shown to have obvious effects on the nutrition and health of the brain and treatment of brain diseases in recent years. Bioactive peptides are considered to be the main component of these products. Recent studies have shown that animals treated with cerebroprotein hydrolysate peptides achieve better learning performance within a few days, but the mechanism of this effect is complex (Zou et al., 2015). Cerebroprotein hydrolysate was prepared in our laboratory, which has obtained a national invention patent (Du et al., 2015). This study established a mouse model of learning and memory impairment and investigated the effect and mechanism of action of cerebroprotein hydrolysate on learning and memory in mice.

Genetics and Molecular Research 15 (3): gmr.15038804 


\section{MATETIAL AND METHODS}

\section{Materials, reagents, and instruments}

\section{Animals}

Fifty-six healthy, male ICR mice, weighing $20 \pm 2 \mathrm{~g}$ from the Laboratory Animal Center of Jilin University were used in the study [laboratory animal license No. SCXK-(Kat) 20140003].

\section{Preparation of cerebroprotein hydrolysate}

Cerebroprotein hydrolysate was prepared in our laboratory, using optimal conditions for composite enzymatic hydrolysis (Du et al., 2015). The enzymes were made from flavor protease and pepsin with a mass ratio of $6: 1-2: 1$ in a pig brain tissue solution, with a $\mathrm{pH}$ of $1-5$, at $37^{\circ} \mathrm{C}$, and a hydrolysis time of $2-10 \mathrm{~h}$. Cerebroprotein hydrolysate was composited with peptides and polypeptides of molecular weight less than $1 \mathrm{kDa}$, with large molecular impurities removed with a nanofiltration membrane filter for impurities, such as pyrogen, after centrifugation.

\section{Reagents}

The materials included: piracetam (Naofukang) (Shenyang First Pharmaceutical Co. Ltd., Northeast Pharmaceutical Group, batch No. 20120804); injections of scopolamine hydrobromide (Changchun Branch, Shenyang Co. Ltd., Sinopharm Group, batch No. 20120801); acetylcholinesterase (AChE) kits; $\gamma$-aminobutyric acid ester (GABA) kits, $\mathrm{Na}^{+}-$ $\mathrm{K}^{+}$-ATPase kits; glutamic acid (Glu) kits (Shanghai Shangle Institute of Biological Products); malondialdehyde (MDA) kits; and superoxide dismutase (SOD) kits (Nanjing Jiancheng Institute of Biological Products, batch No. 20140109, 20140316).

\section{Instruments}

The instruments included an SPX-250B-Z constant temperature biochemical incubator (Shanghai Boyuan Industry Co. Ltd.), a 5430R hypothermia high speed centrifuge (Eppendorf Company, United States), an Infinite M200 microplate (TECAN), a Morris water-maze test device, a BA-200 mouse shuttle-avoidance instrument, and a DT-200 mouse step-down test instrument (Chengdu Thai Union Technology Co., Ltd.).

\section{Animal grouping and drug administration}

After being trained for 3 days, 56 mice without significant differences in their escape latency were screened and divided into 4 groups: 1$)$ the normal control group (CON), treated with normal saline $20 \mathrm{~mL} / \mathrm{kg}$; 2) the model group (M), treated with normal saline $20 \mathrm{~mL} / \mathrm{kg}$; 3 ) the positive control group (PC), treated with piracetam $(540 \mathrm{mg} / \mathrm{kg})$, and 4) the cerebroprotein hydrolysate group $(\mathrm{CH})$, treated with cerebroprotein hydrolysate $105 \mathrm{mg} / \mathrm{kg}$. There were 14 mice in each group. All agents were intragastrically administered once daily for 35 days.

Genetics and Molecular Research 15 (3): gmr.15038804 


\section{Learning and memory training and testing in the Morris water maze}

Before the water-maze test, all mice, except those in the normal control group (which were given normal saline), were given scopolamine hydrobromide $(5 \mathrm{mg} / \mathrm{kg}$ ) by intraperitoneal injection to establish a mouse learning and memory impairment model ${ }^{[10]}$. The Morris watermaze test was composed of two phases, which were conducted in a round pool and recorded using an automated video analysis system. After water was poured into the round pool (diameter: $80 \mathrm{~cm}$, height: $30 \mathrm{~cm}$ ), titanium dioxide was added so the water was not transparent. The water maze was divided into 4 quadrants and the temperature was kept at $25^{\circ} \mathrm{C}$. A white circular platform (diameter: $10 \mathrm{~cm}$, height: $28 \mathrm{~cm}$ ) was placed approximately $1-2 \mathrm{~cm}$ below the water surface in the third quadrant. Just before the test, the bodies of the mice were dyed yellow with picric acid. The water-maze test was performed on 7 consecutive days. From the 1 st to 6 th days, a position navigation test was conducted, in which the mice were gently put into the water at entry points in the 1st, $2 \mathrm{nd}, 3 \mathrm{rd}$, and 4th quadrants, with the head of the mouse facing the wall. The escape latency (time to step onto the platform) of the mice was recorded up to $120 \mathrm{~s}$, and the average of the escape latencies on each trial was calculated as an index to evaluate the learning and memory ability of the mice. On the 7th day, a spatial-probe test was conducted, in which the platform was removed and the mice were put into the water only in a fixed quadrant; the time for the mice to cross the original platform location within $120 \mathrm{~s}$ and number of crossings were recorded to evaluate the learning and memory ability of the mice.

\section{Passive avoidance behavior-step-down test}

The step-down test was conducted following the Morris water-maze test (Tota et al., 2010). On the 1st day, each mouse was put into the chamber of a step-down instrument to acclimate to the environment for $3 \mathrm{~min}$. A stimulus of $32 \mathrm{~V} \mathrm{AC}$ was then given to the mouse through a copper grid on which the mouse was standing. Most of the mice jumped onto an insulated platform to escape the electric shock after they received it; the mice could jump back onto the copper grid and then back onto the insulated platform repeatedly. The mice were trained in this way for $5 \mathrm{~min}$, and the number times that the mice stepped down from the platform (called the number of errors) was recorded as an index to evaluate the learning ability of mice. Twentyfour hours later, the same test was conducted again, with the mouse placed on the insulated platform first. The $\mathrm{AC}$ was then turned on, and the time it took for the mouse to step down from the platform for the first time was recorded as the step-down latency; the number of times it stepped-down within 5 min was recorded as the number of errors. The latency and number of errors were both used as indices to evaluate the memory ability of the mice.

\section{Determination of the biochemical indices}

After the Morris water-maze test and the step-down test, the mice in all the groups were sacrificed using rapid decapitation, and their brain tissue was removed. The brain tissue was accurately weighed and prepared into whole-brain homogenates with normal saline at a ratio of 1:9 in an ice bath. The homogenates were centrifuged at $4000 \mathrm{round} / \mathrm{min}$ at $4^{\circ} \mathrm{C}$ for 10 min to make the supernatants that were used as the detection samples. According to their respective kit instructions, the MDA content and SOD activity in the brain tissue of the mice were determined; AChE, $\mathrm{Na}^{+}-\mathrm{K}^{+}$-ATPase, and GABA activity, and the Glu content of the brain tissue were detected using the ELISA method described in the kit instructions.

Genetics and Molecular Research 15 (3): gmr.15038804 


\section{Hematoxylin eosin (H\&E) staining of brain tissue and pharmacological observation}

The hippocampal tissue of the mice was fixed with $10 \%$ neutral formalin, embedded within paraffin, prepared into slices, dyed with $\mathrm{H} \& \mathrm{E}$, and the morphological changes of the brain tissue were observed under a light microscope.

\section{Statistical analysis}

The data were analyzed with the SPSS 16.0 statistical software. The data are reported as means $\pm \mathrm{SE}$, and $t$-tests were used to compare the data between groups.

\section{RESULTS}

\section{Effects of cerebroprotein hydrolysate on learning and memory ability in spatial orientation}

\section{Place navigation test}

There was no significant difference in escape latency between the different groups of mice during the first 3 days. From the 4 th to the 6 th day, the escape latency of mice in the model group increased significantly, compared with the latency in the normal control group $(\mathrm{P}<0.05)$. Compared with the model group, the escape latency of mice in the positive control group and the cerebroprotein hydrolysate group was significantly shorter $(\mathrm{P}<0.05)$.

\section{Spatial probe test}

The number of mice to cross the platform in the positive control and cerebroprotein hydrolysate-treated groups was significantly higher than that in the model group $(\mathrm{P}<0.05)$. The results are shown in Table 1.

Table 1. Results of Morris water-maze test in mice (means $\pm \mathrm{SEM}, \mathrm{N}=14$ ).

\begin{tabular}{l|c|c|c|c}
\hline \multirow{2}{*}{ Group } & \multicolumn{3}{|c|}{ Escape latency } & No. of crossings of the platform \\
\cline { 2 - 5 } & 1st day & 5th day & 6th day & 7 th day \\
\hline CON & $36.84 \pm 16.02$ & $39.76 \pm 18.38$ & $35.31 \pm 14.59$ & $2.86 \pm 1.51$ \\
\hline M & $70.52 \pm 36.06^{*}$ & $71.13 \pm 34.15^{*}$ & $76.24 \pm 31.78^{*}$ & $2.03 \pm 1.22^{*}$ \\
\hline CH & $26.21 \pm 20.38^{\#}$ & $28.79 \pm 15.57^{\#}$ & $20.92 \pm 15.31^{\#}$ & $5.43 \pm 2.59^{* \#}$ \\
\hline PC & $50.47 \pm 33.70^{\#}$ & $45.91 \pm 44.66^{\#}$ & $22.92 \pm 24.24^{\#}$ & $5.14 \pm 1.66^{* \#}$ \\
\hline
\end{tabular}

$* \mathrm{P}<0.05$, compared with $\mathrm{CON}$ group; ${ }^{*} \mathrm{P}<0.05$, compared with $\mathrm{M}$ group. $\mathrm{CON}=$ normal control group; $\mathrm{M}=$ model group; $\mathrm{CH}=$ cerebroprotein hydrolysate group; $\mathrm{PC}=$ positive control group.

\section{Effects of cerebroprotein hydrolysate on the memory of mice}

As shown in Table 2, the step-down latency of the model group was significantly shorter than the latency of the normal control group. Compared with the model group, the latency was significantly longer and number of errors was significantly lower in the cerebroprotein hydrolysate group on the 2 nd day $(\mathrm{P}<0.05)$; the number of errors and latency of the positive group were not significantly different. 
Table 2. Results of the passive avoidance test-step-down test (means \pm SEM, $N=14$ ).

\begin{tabular}{l|c|c|c}
\hline Group & Number of errors (1st day) & Latency (2nd day) & Number of errors (2nd day) \\
\hline CON & $5.07 \pm 2.46$ & $23.86 \pm 17.16$ & $7.07 \pm 3.17$ \\
\hline M & $7.43 \pm 2.77$ & $17.43 \pm 10.87^{*}$ & $8.36 \pm 2.84$ \\
\hline CH & $5.29 \pm 3.20$ & $57.71 \pm 110.01^{\#}$ & $8.14 \pm 3.82^{\#}$ \\
\hline PC & $4.79 \pm 2.33^{\#}$ & $16.21 \pm 9.56$ & 2.79 \\
\hline
\end{tabular}

$* \mathrm{P}<0.05$, compared with the normal control group; ${ }^{*} \mathrm{P}<0.05$, compared with the model group. $\mathrm{CON}=$ normal control group; $\mathrm{M}=$ model group; $\mathrm{PC}$ = positive control group; $\mathrm{CH}=$ cerebroprotein hydrolysate group.

\section{Effects of cerebroprotein hydrolysate on the biochemical indices in the brain tissue of mice}

As shown in Tables 3 and 4, SOD and $\mathrm{Na}^{+}-\mathrm{K}^{+}$-ATPase activity, and GABA and Glu content were significantly reduced $(\mathrm{P}<0.05)$, and MDA content and AChE activity were significantly increased in the brain tissue of the mice in the model group when compared with mice in the normal control group $(\mathrm{P}<0.05)$. Compared with mice in the model group, GABA content was significantly higher $(\mathrm{P}<0.05)$; AChE activity and Glu and MDA content were reduced significantly $(\mathrm{P}<0.05)$ in the brain tissue of mice treated with the cerebroprotein hydrolysate; SOD and $\mathrm{Na}^{+}-\mathrm{K}^{+}$-ATPase activity in the brain tissue were increased significantly $(\mathrm{P}<0.05)$.

Table 3. Effects of cerebroprotein hydrolysate on SOD and $\mathrm{Na}^{+}-\mathrm{K}^{+}$-ATP activity and MDA content in the brain tissue of mice (means $\pm \mathrm{SEM}, \mathrm{N}=14$ ).

\begin{tabular}{l|c|c|c}
\hline Group & MDA $(\mu \mathrm{mol} / \mathrm{mg})$ & SOD $(\mathrm{U} / \mathrm{mg})$ & $\mathrm{Na}^{+}-\mathrm{K}^{+}-\mathrm{ATPase}(\mu \mathrm{mol} / \mathrm{mg})$ \\
\hline CON & $7.84 \pm 1.00$ & $119.72 \pm 16.37$ & $2.72 \pm 0.09$ \\
\hline M & $11.50 \pm 1.57^{*}$ & $60.14 \pm 38.47^{*}$ & $1.17 \pm 0.17^{*}$ \\
\hline CH & $7.91 \pm 1.380^{\#}$ & $102.92 \pm 14.46^{\#}$ & $2.05 \pm 0.15^{\#}$ \\
\hline PC & $10.62 \pm 1.6$ & $84.12 \pm 54.93^{\#}$ & $2.25 \pm 0.15^{\#}$ \\
\hline
\end{tabular}

$* \mathrm{P}<0.05$, compared with the normal control group; ${ }^{\#} \mathrm{P}<0.05$, compared with the model group. CON $=$ normal control group; $\mathrm{M}=$ model group; $\mathrm{PC}=$ positive control group; $\mathrm{CH}=$ cerebroprotein hydrolysate group.

Table 4. Effects of cerebroprotein hydrolysate on GABA and Glu content and AChE activity in the brain tissue of mice (means $\pm \mathrm{SEM}, \mathrm{N}=14$ ).

\begin{tabular}{l|c|c|c}
\hline Group & AChE $(\mathrm{U} / \mathrm{mg})$ & GABA $(\mathrm{ng} / \mathrm{mL})$ & Glu $(\mathrm{ng} / \mathrm{mL})$ \\
\hline CON & $1.37 \pm 0.10$ & $1.51 \pm 0.09$ & $1.00 \pm 0.16$ \\
\hline M & $1.51 \pm 0.10^{*}$ & $1.27 \pm 0.16^{*}$ & $1.42 \pm 0.12^{*}$ \\
\hline CH & $1.13 \pm 0.08^{*}$ & $1.64 \pm 0.15^{\#}$ & $1.10 \pm 0.12^{\#}$ \\
\hline PC & $1.03 \pm 0.18^{*}$ & $1.25 \pm 0.04^{*}$ & $1.28 \pm 0.16^{\#}$ \\
\hline
\end{tabular}

${ }^{*} \mathrm{P}<0.05$, compared with the normal control group; ${ }^{*} \mathrm{P}<0.05$, compared with the model group. $\mathrm{CON}=$ normal control group; $\mathrm{M}=$ model group; $\mathrm{PC}$ = positive control group; $\mathrm{CH}=$ cerebroprotein hydrolysate group.

\section{Effects of cerebroprotein hydrolysate on damage to hippocampal neurons in mice}

HE staining showed that the hippocampal structure was intact under low microscopic magnification. The two sides were symmetric, the partition of the different areas differed significantly, and the pyramidal cells were arranged in more and denser levels (Figure 1A). Under high microscopic magnification, the nuclei of nerve cells were clearly visible (Figure

Genetics and Molecular Research 15 (3): gmr.15038804 
1B) in mice in the normal control group, compared with the model group. In the model group, the hippocampal cells were smaller, boundaries of cell bodies were clearer because of deeper staining, number of nerve cells was reduced significantly, arrangement of the nerve cells was scattered, number of free cells was higher, structure of the cells was unclear or had disappeared, and vacuolar degeneration in some cells and the proliferation of glial cells could be seen (Figure 1C and D). Compared with the mice in the model group, the pathological changes of the nerve cells in the positive group and the cerebroprotein hydrolysate group were significantly less (Figure 1E, F, G and H).
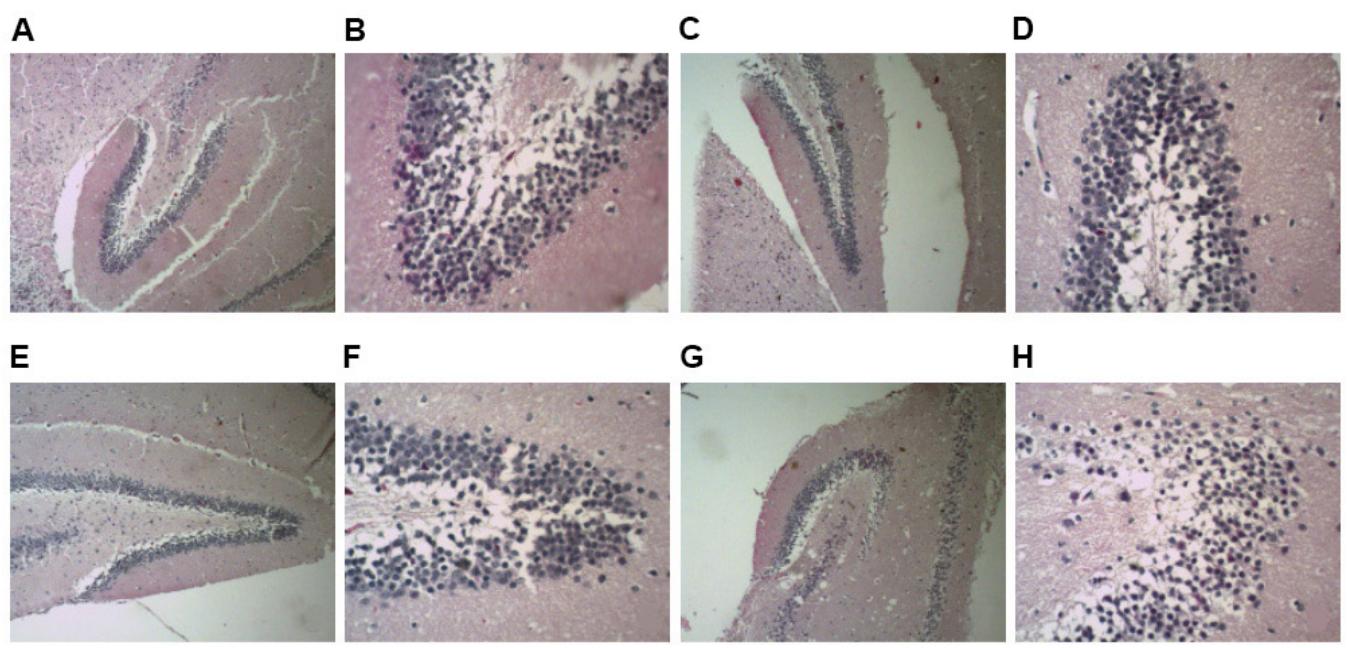

Figure 1. A.-H. H\&E staining of hippocampal structures. $\mathrm{CON}=$ normal control group; $\mathrm{M}=$ model group; $\mathrm{PC}=$ positive control group; $\mathrm{CH}=$ cerebroprotein hydrolysate group.

\section{DISCUSSION}

Geriatric diseases, such as stroke and dementia, are often characterized by a decline in learning and memory ability, and the recovery of learning and memory ability directly influences the rehabilitation of geriatric diseases. Cerebroprotein hydrolysate has been shown to be reliably safe and have a curative effect on neurological deficits resulting from cerebrovascular diseases in clinical samples. This study focused on the effect and mechanism of cerebroprotein hydrolysate on learning and memory ability in mice, to lay the theoretical and experimental foundation for applications to improve learning and memory in the elderly.

Behavioral experimentation is one of the main methods for evaluating learning and memory. The cholinergic system plays a special role in cognitive functions, including learning and memory, and scopolamine hydrobromide (SCOP) is a central anti-cholinergic agent that causes dysfunction of the cholinergic system. The amount of acetylcholine (ACh) in the brain is deficient in patients with Alzheimer's disease (AD), and it is believed that a deficit of central cholinergic nerves may be an important cause of AD (Tota et al., 2012; Ferreira-Vieira et al., 2016). In this study, $5.0 \mathrm{mg} / \mathrm{kg}$ SCOP was injected intraperitoneally into mice to create a mouse model of learning and memory impairment. The behavioral experiments included the classic Morris water-maze and step-down tests. The water-maze test 
was intended primarily to measure spatial learning and memory ability, and the step-down test was intended to measure passive avoidance. It was thought that the measures obtained by the two tests would objectively reflect the effects of cerebroprotein hydrolysate on the learning and memory ability of mice and learning and memory impairment induced by SCOP. In addition, pathological changes in the hippocampus were observed following HE staining as a visual index for the effects of SCOP. The Morris water-maze and step-down tests showed that learning and memory ability was impaired, and that the karyopyknosis of hippocampal nerve cells and number of cells were reduced in the model mice, indicating that the mouse model was successfully established. After treatment with cerebroprotein hydrolysate, the results of the two behavioral tests consistently indicated that the learning and memory ability of mice was improved. Furthermore, the pathology report suggested there was a recovery of the pyramidal cells in the hippocampus after cerebroprotein hydrolysate treatment, indicating that cerebroprotein hydrolysate improved the learning and memory ability of mice after SCOPinduced impairment.

Peroxidation injury caused by oxygen free radicals is one of the most important factors in geriatric diseases such as AD. During the process of aging, the nerve cells are oxidized to produce a large number of free radicals that damage cell membranes, causing cell apoptosis, which can reduce the ability to learn (Antonio-García and Massó-Gonzalez, 2008). SOD is an important enzyme that scavenges free radicals and its activity is an important indicator for evaluating the antioxidant capacity of the body. MDA is one of the major metabolites induced by free radicals, and it can cause denaturation of biomembranes and mutation of DNA. Moreover, MDA may decrease the activity of SOD (Li et al., 2013, 2015). This study found that cerebroprotein hydrolysate significantly decreased MDA levels and simultaneously increased the activity of SOD in the brain tissue of mice, indicating that cerebroprotein hydrolysate may significantly improve the scavenging of oxygen free radicals in brain tissue after SCOP-induced impairment of learning and memory. It is well known that free radicals and the metabolites induced by them can cause damage to the membrane of cells and decrease the activity of widely distributed $\mathrm{Na}^{+}-\mathrm{K}^{+}$-ATPases. This can catalyze the hydrolysis of ATP and promote the release of free energy stored in ATP to drive the active transport of $\mathrm{Na}^{+}, \mathrm{K}^{+}$, and other substances (Xie, 1989). The results showed that cerebroprotein hydrolysate can increase $\mathrm{Na}^{+}-\mathrm{K}^{+}$-ATPase activity to promote the release of neurotransmitters associated with learning and memory, regulate the excitability of neurons, enhance brain function, and improve the quality and quantity of brain activity, consistent with numerous prior reports (Teng et al., 2014). This may be another important mechanism through which cerebroprotein hydrolysate can improve learning and memory in mice.

Biological studies have found that the central cholinergic system is closely linked to learning and memory. The normal functioning of central cholinergic nerves is essential for learning and memory, and the impairment or decline of this function can affect the efficiency of learning and memory ( $\mathrm{Li}$ et al., 2013). AChE is a specific hydrolase of ACh and one of the key substances in biological activity normally controlled by ACh. The activity of AChE is higher in cholinergic neurons; hence, their activity should reflect the activity of AChE. After the administration of cerebroprotein hydrolysate, the activity of AChE was reduced in mice in this study, suggesting that cerebroprotein hydrolysate may have reduced the impairment of learning and memory by improving function of ACh neurons in the mice (de Freitas, 2010). Complex neurophysiological and neurobiochemical mechanisms are involved in learning and memory processes, and the mechanisms are closely related, not only to the central cholinergic

Genetics and Molecular Research 15 (3): gmr.15038804 
nervous system, but also to central amino acid neurotransmitters. Asparaginate (Asp) and Glu are excitatory amino acids and Gly and GABA are inhibitory amino acids, which play important roles in maintaining the balance of excitation and inhibition in the central nervous system (Luo et al., 2011; Wang et al., 2014). Changes in the level of central amino acids in AD, especially the imbalance between Glu and GABA, are key factors leading to neuron injury (Cui et al., 2015). In our study, cerebroprotein hydrolysate reduced the level of Glu and the ratio of Glu/GABA in the brain tissue of mice to regulate the Glu/GABA learning and memory regulation system and reduce the excitotoxicity of Glu, which may be one of the mechanisms through which cerebroprotein hydrolysate reduced the learning and memory impairment of the mice.

In summary, cerebroprotein hydrolysate can reduce learning and memory impairment induced by SCOP in mice and, thereby, improve learning and memory ability. This may be related to its ability to reduce the damage induced by oxygen free radicals, improving ACh function, and modulating the Glu/GABA learning and memory regulation system to attenuate the excitotoxicity caused by Glu.

\section{Conflicts of interest}

The authors declare that they have no conflict of interest.

\section{ACKNOWLEDGMENTS}

Research funded by project "20160441001SC" supported by Sci-tech Department of Jilin Province, project "20156409" supported by Sci-tech Department of Jilin City and project "2014Z088" the Health Department of Jilin Province.

\section{REFERENCES}

Antonio-García MT and Massó-Gonzalez EL (2008). Toxic effects of perinatal lead exposure on the brain of rats: involvement of oxidative stress and the beneficial role of antioxidants. Food Chem. Toxicol. 46: 2089-2095. http:// dx.doi.org/10.1016/j.fct.2008.01.053

Bannerman DM, Niewoehner B, Lyon L, Romberg C, et al. (2008). NMDA receptor subunit NR2A is required for rapidly acquired spatial working memory but not incremental spatial reference memory. J. Neurosci. 28: 3623-3630. http:// dx.doi.org/10.1523/JNEUROSCI.3639-07.2008

Cui SQ, Wang Q, Zheng Y, Xiao B, et al. (2015). Puerarin protects against damage to spatial learning and memory ability in mice with chronic alcohol poisoning. Braz. J. Med. Biol. Res. 48: 515-522. http://dx.doi.org/10.1590/1414$\underline{431 X 20144250}$

Du PG, Wang ML, An LP, Li HY, et al (2015). Cerebroprotein hydrolysate and its preparation methods. ZL 201410409501.5.

Ferreira-Vieira TH, Guimaraes IM, Silva FR and Ribeiro FM (2016). Alzheimer's disease: Targeting the Cholinergic System. Curr. Neuropharmacol. 14: 101-115. http://dx.doi.org/10.2174/1570159X13666150716165726

de Freitas RM (2010). Lipoic Acid increases hippocampal choline acetyltransferase and acetylcholinesterase activities and improvement memory in epileptic rats. Neurochem. Res. 35: 162-170. http://dx.doi.org/10.1007/s11064-009-0041-6

García EH, Guzmán DC, Olguín HJ, Jiménez FT, et al. (2011). Effect of cerebrolysin on the levels of glutathione and 5-HT in different regions of rat brain in presence of dantrolene. Biomed Aging Pathol. 1: 169-174. http://dx.doi. org/10.1016/j.biomag.2011.06.010

Keilhoff G, Lucas B, Pinkernelle J, Steiner M, et al. (2014). Effects of cerebrolysin on motor-neuron-like NSC-34 cells. Exp. Cell Res. 327: 234-255. http://dx.doi.org/10.1016/j.yexcr.2014.06.020

Li C, Wang Q, Li L, Liu Y, et al. (2015). Arachidonic acid attenuates learning and memory dysfunction induced by repeated isoflurane anesthesia in rats. Int. J. Clin. Exp. Med. 8: 12365-12373.

Genetics and Molecular Research 15 (3): gmr.15038804 
Li YS, Hong YF, He J, Lin JX, et al. (2013). Effects of magnolol on impairment of learning and memory abilities induced by scopolamine in mice. Biol. Pharm. Bull. 36: 764-771. http://dx.doi.org/10.1248/bpb.b12-00880

Luo J, Min S, Wei K, Li P, et al. (2011). Propofol protects against impairment of learning-memory and imbalance of hippocampal Glu/GABA induced by electroconvulsive shock in depressed rats. J. Anesth. 25: 657-665. http://dx.doi. org/10.1007/s00540-011-1199-Z

Novak PH, Moessler H, Gusev EI and Guekht AB (2009). Cerebrolysin in vascular dementia: a randomized, placebo controlled study. Alzheimers Dement. 5: P249. http://dx.doi.org/10.1016/j.jalz.2009.04.255

Sharp N, Ellard M, Hirschowitz L, Malthouse S, et al. (2002). Successful microwave ablation of endometrial carcinoma. BJOG 109: 1410-1412. http://dx.doi.org/10.1046/j.1471-0528.2002.01081.x

Teng J, Xu Z, Zhang J and Li J (2014). Effect of yizhitongxuan decoction on learning and memory ability, Gaq/11 expression and $\mathrm{Na}(+)-\mathrm{K}(+)-\mathrm{ATP}$ enzyme activity in rat models of Alzheimer's disease. J. Tradit. Chin. Med. 34: 470-476. http://dx.doi.org/10.1016/S0254-6272(15)30049-2

Tota S, Awasthi H, Kamat PK, Nath C, et al. (2010). Protective effect of quercetin against intracerebral streptozotocin induced reduction in cerebral blood flow and impairment of memory in mice. Behav. Brain Res. 209: 73-79. http:// dx.doi.org/10.1016/j.bbr.2010.01.017

Tota S, Hanif K, Kamat PK, Najmi AK, et al. (2012). Role of central angiotensin receptors in scopolamine-induced impairment in memory, cerebral blood flow, and cholinergic function. Psychopharmacology (Berl.) 222: 185-202. http://dx.doi.org/10.1007/s00213-012-2639-7

Wang T, Li Y, Zhao P, Wang J, et al. (2014). Effects of oxysophoridine on amino acids after cerebral ischemic injury in mice. Ann. Indian Acad. Neurol. 17: 313-316. http://dx.doi.org/10.4103/0972-2327.138513

Xie JP (1989). The Overview Research of (Na +-K +)-ATPase. Sheng Wu Hua Xue Yu Sheng Wu Wu Li Jin Zhan 16: 256-257.

Zhang H, Zhang X and Xu B (2005). Analysis and determination of biological activity of short-chain peptides from porcine brain hydrolysate. J. Pharm. Biomed. Anal. 37: 333-339. http://dx.doi.org/10.1016/j.jpba.2004.10.031

Zou Y, Feng W, Wang W, Chen Y, et al. (2015). Protective Effect of Porcine Cerebral Hydrolysate Peptides on Learning and Memory Deficits and Oxidative Stress in Lead-Exposed Mice. Biol. Trace Elem. Res. 168: 429-440. http:// dx.doi.org/10.1007/s12011-015-0329-0

Zuber VL (1991). The effect of cerebrolysin on the metabolism of brain phospholipids in growing animals with experimental demyelination. Nerv. Sist. 30: 85-90.

Genetics and Molecular Research 15 (3): gmr.15038804 